\title{
Evaluation Model for Selection of Advanced Manufacturing Technologies
}

\author{
H. S. C. Perera
}

\begin{abstract}
Implementation of Advanced Manufacturing Technologies (AMT) has become a popular strategy among many industries to face the growing competition. Selection of AMT purely based on economic benefits has been challenged due to other factors such as strategic benefits. This paper presents decision making framework for selection of AMT. Factors influenced on Advanced Manufacturing Technology selection were identified under three categories. economic indicators, strategic benefits and risk. Sub-criteria of each category were further identified. Selection of the best AMT led to a multi-criteria decision making problem as alternative technologies should be evaluated based on many criteria. An Analy tic Hierarchy Process (AHP) model was developed for ranking the alternative AMTs. An example of a case is presented to show the actual implementation of the AHP model.
\end{abstract}

Keywords: Advanced Manufacturing Technology, Analytic Hierarchy Process, Selection of AMT

\section{Introduction}

Many firms have adopted advanced manufacturing technologies (AMT) to improve operational performance and to achieve competitive success. AMT represents a wide variety of modern, mainly computer-based systems coupled with new organizational practices. Some industrialists and economists believe that AMT has great potential to offer manufacturing companies, with many tangible and intangible benefits [1]. These benefits include earlier entrance to market, ability to respond more quickly to changing customer needs and higher quality products with improved consistency and reliability among other things [2]. However, results of several empirical studies indicate that implementing AMT has often not been either as successful or as straight forward as expected $[3,4,5,6]$. Among the many reasons for failure, there is some indication that faulty or inadequate investment justification practices can result in firms not recognizing or considering some benefits which the AMT may indeed be capable of bestowing $[6,7,8]$.

The benefits of AMT are significant but there are several internal and external factors inhibiting the success of AMT investment decisions. Lack of readily accessible and acceptable methods for appraising all the benefits offered by the AMT is one of the major problems [1]. Moreover, some manufacturers hold the view that the adoption of AMT involves a high level of investment, and its payback period is usually longer than that traditionally required by business enterprises. Due to this reason, management may adopt a rather conservative policy, and hence refuses to consider AMTs, even though they could potentially benefit the firm [9]. Because of the potentially high investments in AMT and the moderate-to-high risk involved in adopting these technologies, there should be an adequate economic analysis and justification method to assist companies in selecting the appropriate technology, most suited to their operations and business objectives. What makes the justification process challenging is inability to incorporate both tangible and intangible benefits of AMT investment in the decision making framework. Many benefits expected from these AMT investments lie not only in the area of cost reduction but in areas of strategic benefits such as improved flexibility, shorter time to market and increased adaptability to changing market conditions that are hard to quantify.

Complexity arises due to the large number of decision criteria and the existence of both tangible and non-tangible factors. Use of economic justification methodologies, adequate

Eng. (Dr.) H.S.C. Perera, B.Sc.Eng. (Morntuzua), M.Eng (AIT), D.Eng. (AIT), CEng, MIE (Sri Lanka), Senior Lecturer, Department of Manngement of Technology, Unizersity of Moratinoa. 
for short-term project is not appropriate for evaluating advanced manufacturing technologies due to the inability to quantify and establish relationships with intangible strategic benefits $[10,11,12]$. On the other hand manufacturers consider different types advanced manufacturing technologies which give benefits differently. For example, while AMT 1 is giving more strategic benefits AMT 2 can give more economic benefits. In this situation, decision maker wants to prioritize advanced manufacturing technologies in order to select the best AMT based on the preferential criteria of the organization. Therefore it is essential to use appropriate decision making process which can incorporate both strategic and economic benefits. This study develops a decision making framework which incorporates important economic and strategic decision attributes.

\section{Literature Review}

The advanced manufacturing technologies are broadly classified into three main groups as stand-alone systems, intermediate systems, and integrated systems [11]. This classification scheme links technologies that have similar benefits and costs. Companies must ascertain which technologies can fulfil their objectives and identify the technologies belonging to a system as shown in Table 1 [9].

O'Brien and Smith [13] indicate that companies adopt advanced manufacturing technologies due to various reasons: adding capacity, replacement of obsolete technologies, exploiting opportunities through new technology, etc.

Several techniques for investment justification of AMT have been advanced. Much of the literature indicate that AMT justification can be grouped into three categories: (1) economic approach - involving the classical financial justification techniques of payback period $(\mathrm{PP})$, return-on-investment (ROI), internal rate of return (IRR), and net present value (NPV); (2) strategic approach - involving analysis of competitive advantage, business objectives, research and development objectives and technical importance; and (3) analytic approach involving value analysis, portfolio analysis and risk analysis [14].
Table 1 - Classification of Technologies(Adopted from [9])

\section{Stand-alone systems}

1. Design and engineering technologies Computer-aided design (CAD) Rapid prototyping Computer-aided process planning (CAPP)

2. Fabricating/machine and assembly technologies

$\mathrm{NC} / \mathrm{CNC}$ or DNC machines

Materials working laser (MWL)

Pick-and-place robots

Other robots

\section{Intermediate systems}

3. Automated material handling technologies Automatic storage and retrieval systems (AS/RS)

Automated material handling systems (AMHS)

4. Automated inspection and testing systems Automated inspecting and testing equipment (AITE)

Integrated systems

5. Flexible manufacturing technologies Flexible manufacturing cells/systems (FMC/FMS)

6. Computer-integrated manufacturing systems

Computer-integrated manufacturing (CIM)

7. Logistic related systems

Just-in-time (JIT)

Material requirements planning

(MRP)

Manufacturing resources planning (MRPII)

Enterprise resource planning (ERP)

\subsection{Economic justification approaches}

Some newly industrialized countries have a relatively low labour cost but highly motivated workforce and generous supply of raw material, so it often makes economic justification of projects difficult [15]. There exist a number of formulae and approaches that companies use for the economic justification of advanced manufacturing technologies. Many companies use simple economic indicators such as payback period (PBP), return on investment (ROI), internal rate of return (IRR), net present value (NPV), and so on, used in situations where they are assuming no uncertainty $[16,17]$. 
Fotsch [16] reports that the payback period (PBP) technique is the most popular method of AMT appraisal. Return on investment (ROI) is the second most popular technique being used for AMT appraisal according to Fotsch [16]. However, Primrose [18] points out that since ROI does not measure the economic value of the project, it has more disadvantages than the payback method. DCF techniques, NPV and IRR are considered to be more effective than ROI and PBP.

Many researchers $[18,19,20]$ point out that discounted cash flow approaches should always be applied for the justification of AMT but, for most firms, the discount rate should be lower than that required for conventional projects. Primrose [18] and Slagmulder and Bruggeman [21] believe that both NPV and IRR should be provided to allow better comparisons between projects. However, Baldwin [22] argues that DCF is inherently biased against technological capital investment. Furthermore, they believe that the widespread use of these methods has led to a decline in the level of capital investment. In addition, DCF techniques have some drawbacks such as conceptual weakness, inability to evaluate strategic investments with future growth opportunities, and especially biased against long term projects [23].

\subsection{Strategic justification approaches}

Strategic approaches are less technical than the economic and analytic approaches, but they are frequently used in combination with them. The advantage of the strategic approaches is their direct link to the organizational goals. A disadvantage is the possibility of overlooking the economic and tactical impact of the AMT, myopically focusing entirely on the strategic impact. However, if a strategic approach is used for evaluation of AMT, the economic implications should also be checked for a robust decision [24].

There are several commonly used criteria evaluated in strategic approaches $[9,25]$.

- Technical importance: Technical importance means that the project is a prerequisite for a crucial follow-on activity. It may have negligible returns, or even disadvantages, but later, more desirable work cannot be attempted without implementing this activity first.
- Business objectives: In justifying the business a firm can check whether the project achieves the firm's business objectives or not.

- Competitive advantage: Competitive advantage can be explained as the opportunity existing for the firm to gain a significant advantage over its competitors by implementing the AMT project. The advantage may not belong to one of the strategic business objectives of the firm but it is very important for the company to go forward.

- $\quad$ Research and development: Treating a project as an R\&D investment admits that it may fail but it holds sufficient strategic promise to justify the investment. The point is that one of many such projects will be successful and provide returns to the firm to compensate all the failures.

\subsection{Analytic justification approaches}

The analytic techniques are highly quantitative and more complex than the economic techniques. The analytic investment appraisal techniques have been widely used for evaluating intangible strategic benefits. It is because they can collect more information and frequently consider uncertainty and multiple measures and effects. The advantage is that they are more realistic and consider more factors and subjective judgments into account [24]. Data collection and analysis are more time consuming compare to the other methods.

Selection process of AMT is much complex and involved several decision criteria. Analytic techniques normally have the capability to tackle this situation. Several commonly used approaches are described below.

The linear additive model [26] can be applied to justify AMT investment alternatives. Each alternative is ranked by combining the information from independent criteria. The score for each alternative is the summation of the rating assigned to each decision factor multiplied by the weight of that alternative with respect to the decision factor. The alternative with the highest score will eventually be preferred. While this technique represents the importance of each strategic factor by weights determined 
by management, these weights are generally not measured for consistency. Furthermore, the assumption of linear additivity of the weighted scores may not be accurate.

O'Brien and Smith [13] have used Analytic Hierarchy Process (AHP) to select advanced manufacturing technologies. In this method management can give relative importance of the decision criteria and preference for the alternatives through pair-wise comparison. Past studies which used AHP as the analytic tool have used strategic benefits as the criteria for evaluation. However, some other important factors such as economic indicators and risk are not considered in the evaluation process.

Integer programming and goal programming have been used for justification of AMT [24]. In integer programming method, $0-1$ variable represents each project. The project is selected when the set of project total weighted scores is maximized, subject to resource constraints such as capital and facilities [27].

Risk analysis evaluates the robustness of the decision under uncertain conditions. There can be uncertainties in benefits, costs, yields, and capacity, etc. Based on a survey, Sitkin and Pablo [28] highlight that there are two prime risks having a profound impact on decision making behaviour. They are: (1) the probability of variance in the cash flows which are initiated by the project; and (2) the probability of variance in the time taken before such cash flows occur, and in the case of the development of some new technologies, whether they would be feasible, acceptable and suitable. The use of risk analysis, therefore, provides management with extended risk-adjusted capabilities for assessing the feasibility of the AMT project.

\subsection{Remarks on literature}

After carefully reviewing the present literature and problems with the traditional approaches, it appears that the justification of AMT requires a comprehensive analysis. Economic justification should couple with the strategic justification and risk analysis. Many existing methodologies follow sequential approach in justification without considering economic, strategic and risk factors simultaneously. In this context, it may therefore be useful to adopt a multi-criteria decision framework. There are few studies which use the multi-criteria approach in AMT selection. However, these methodologies have mainly considered strategic benefits without giving much attention to economic and risk factors. The next Section discusses the development of a multi-attribute decision model using analytic hierarchy process (AHP).

\section{Model Development}

According to literature review, selection of AMT involves multiple criteria. Alternative advanced manufacturing technologies in consideration should be evaluated against these multiple criteria. In solving multi-criteria decision making problems there are number of techniques used in the literature. Analytic Hierarchy Process (AHP) developed by Satty [29] is a well used and well tested method in solving problems in this nature for many years. The AHP has been well received by all concerned as reported in the literature [30]. Application of this methodology has been found in numerous fields. The general approach of the AHP model is to decompose the problem and make pair-wise comparison of all the elements on a given level with the related elements in the level just above to which it belong. In this study, $\mathrm{AHP}$ is used to develop the decision making model.

\subsection{Proposed criteria for AMT selection}

Literature shows that both economic and strategic factors are important in evaluating the advanced manufacturing technologies. In addition to these criteria, risk of implementation has gained the attention of many researchers. In this study, these three evaluation criteria namely economic factors, strategic factors and risk are used to develop the decision making model. These main criteria can be further decomposed into lower level sub-criteria.

In economic justification payback period (PBP), return on investment (ROI), internal rate of return (IRR) and net present value (NPV) can be identified as the commonly used economic indicators. Therefore these indicators are considered as the sub-criteria of economic factors. As discussed in the literature review, commonly used strategic justification criteria are technical importance, business objectives competitive advantage, research and development $[9,25]$. AMT investment is considered as research and development in order to accommodate the risk 
involved in the investment. In this study, risk is considered as a one of the major criteria so that it is possible to accommodate different aspects of risk. Therefore only technical importance, business objectives and competitive advantage are considered as the sub-criteria of strategic criteria.

It is possible to identify several sub-criteria of risk. Financial risk has gained the attention of many researchers and practitioners. Financial risk is mainly due to inability to attain expected financial gains from AMT implementation. Apart from financial risk other possible risks are organizational risk and the technological risk. Success of AMT will also depend on the ability of the organization to absorb such new technology. There is a possible risk of AMT implementation due to the mismatch of AMT with organizational structure, management practices and culture $[31,32]$. The other risk is that the AMT becomes obsolete as the rate of technological advancement has increased significantly over recent years. Therefore in this study, the risk is divided into three sub-criteria: financial risk, organizational risk, technological risk. Criteria and sub-criteria used for AMT evaluation are presented in Table 2.

\subsection{Analytic Hierarchy Process (AHP) methodology}

Analytic Hierarchy Process (AHP) is a practical approach in solving relatively complex problems. AHP enables the decision maker to represent the simultaneous interaction of many factors in complex, unstructured situation. For the selection of ERP Software, the judgment based on observation is fed into AHP for each criterion and sub-criterion of all level of hierarchy. Pairwise comparisons of criterion at each level are done on a scale of relative importance, 1 reflecting equal weightage and 9 reflecting absolute importance (see appendix for details).

The steps to follow in using the AHP

(1) Define the problem and determine the objective.

(2) Identify the criteria and alternatives to be evaluated.

(3) Structure the hierarchy from the top through the intermediate levels to the lowest level. See Figure 1 for AHP model of the case problem.

(4) Construct a set of pair-wise comparison matrices for each of the lower levels. An element in the higher level is said to be a governing element for those in the lower level, since it contributes to it or affects it. The elements in the lower level are then compared to each other based on their effect on the governing element above. This yields a square matrix of judgments. The pair-wise comparisons are done in terms of which an element dominates another. These judgments are then expressed as integers. If element A dominates over element B, then the whole number integer is entered in row $A$, column B and reciprocal is entered in row $\mathrm{B}$, column $\mathrm{A}$. If the elements being compared are equal, a one is assigned to both positions. (Table 3 shows the pairwise comparison matrix for level 2 criteria in the case implementation).

(5) There are $\mathrm{N}(\mathrm{N}-1) / 2$ judgment required to develop the set of matrices in step 3 (reciprocals are automatically assigned in each pair-wise comparisons).

Table 2 - Criteria Used for AMT Evaluation

Economic Criteria

Payback period [PBP]

Return on investment [ROI]

Internal rate of return [IRR]

Net present value [NPV]

\section{Strategic Criteria \\ Technical importance [TEC]}

Business objectives [BUS]
The length of time required to recover the cost of an investment.

The ratio of money gained or lost on the investment relative to the amount of money invested.

The discount rate that makes the net present value of all cash flows from the investment equal to zero.

The difference between the present value of cash inflows and the present value of cash outflows.

Importance of technology as a prerequisite for follow on activity

Ability to meet business objectives such as reduced cost and market share 
Competitive

advantage [COM]

Advantages

over competitors other than business objectives

\section{Risk}

Financial risk [FIR] Risk of not achieving intended financial gains

Organizational risk Difficulty in technology [ORR]

Technology risk [TER] adoption due to organizational issues Risk of technology obsolescence

(6) Having done all the pair-wise comparisons and entered the data, the consistency is determined using the Eigen value of pairwise comparison matrix.

$\lambda \max =$ Eigen value of pair-wise comparison matrix.

Consistency Index:

$\mathrm{CI}=(\lambda \max -\mathrm{N}) /(\mathrm{N}-1)$

Consistency Ratio:

$(\mathrm{CR})=\mathrm{CI} / \mathrm{RCI}$ corresponding to $\mathrm{N}$

Where, $\mathrm{RCI}=$ Random Consistency Index and $\mathrm{N}=$ Number of elements
Random Index Table

\begin{tabular}{lllcccc}
\hline $\mathrm{N}$ & 1 & 2 & 3 & 4 & 5 & 6 \\
$\mathrm{RCI}$ & 0 & 0 & 0.58 & 0.9 & 1.12 & 1.24 \\
\hline
\end{tabular}

If $\mathrm{CR}$ is less than $10 \%$, judgments are considered consistent. And if CR is greater than $10 \%$, the quality of judgments should be improved to have CR less than or equal to $10 \%$.

(7) Weight for each criterion is determined. To do so, normalize the column of numbers by dividing each entry by the sum of all entries. Take the average of normalized values of each row as the weight for respective criterion of the row.

(8) Steps 4-7 are performed for each set of sub-criteria.

(9) The alternative analysis for the lowest level of sub-criteria to be carried out in the similar manner as above.

(10) Priority score for each alternative is calculated by multiplying each value in sub-criteria by the respective values of higher level criteria weights and then multiplying by the value for each respective alternative and summing the results.

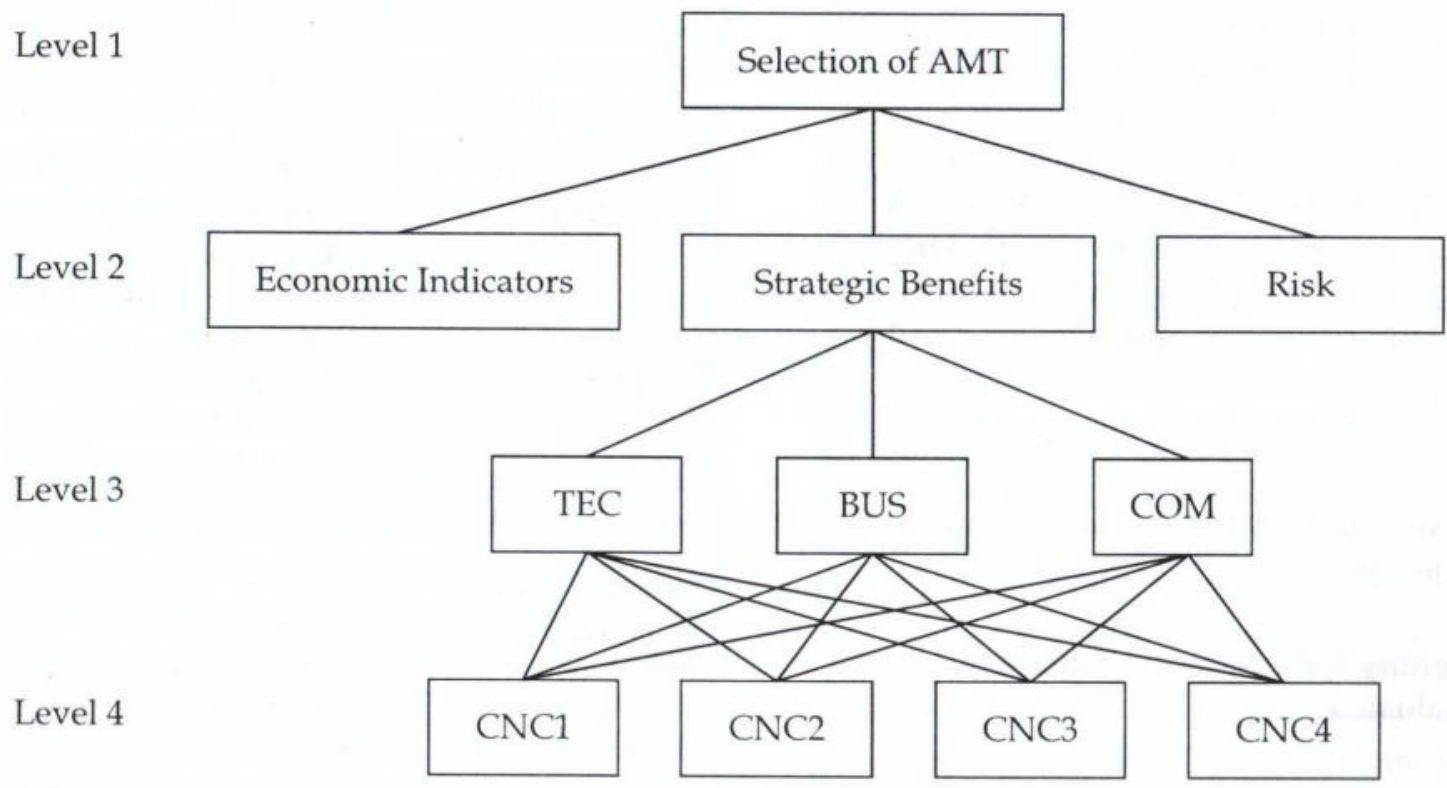

Figure 1 - Schematic Diagram of the AHP Model for AMT Selection 


\section{Case Implementation}

The purpose of the case study was to test the proposed AHP methodology in the field environment. The company considered for the case study was a producer of dies and moulds. It was in the process of acquiring computer numerical control (CNC) machine for upgrading the existing manufacturing capability. Four CNC machines were under considerations. The four $\mathrm{CNC}$ machines are as follows:

CNC1: 3-axis machining centre with smaller cutting table

$\mathrm{CNC2}$ : 3-axis machining centre with larger cutting table

CNC3: 5-axis machine with a rotary table only

CNC4: 5-axis machine with rotary table and spindle

The machines had different capabilities; and hence investments were different. Accountants had determined the economic indicators for four investments. But the management was in the view that the alternative with the best economic indicators might not be the one with most attractive strategic benefits. On the other hand, some mangers argued acquisition of sophisticated 5-axis CNC machines would be risky due to uncertainty of the market growth and lack of human resource capabilities. In this context AHP would be a useful tool to evaluate the alternative AMTs.

\subsection{AHP structure for AMT selection}

AHP model was formulated based on the evaluation criteria and alternative AMTs. The schematic diagram of AHP model is shown in Figure 1. Level 1 of the diagram represents the objective of the problem. Level 2 indicates the major criteria used in the decision making process. Sub-criteria under each major criterion are given in the level 3 . Only the sub-criteria of strategic benefits are shown in the diagram for the clarity. Alternatives to be evaluated are shown in the bottom level (level 4) of the diagram.

\subsection{Pair-wise comparison of criteria and alternatives}

Judgments on the criteria were obtained from four top managers who were involved in selection of AMT. These mangers were from different professional backgrounds (engineering, accounting, etc.) and able to provide the judgments on any criteria involved in the AHP model. The comparison was done asking the question "How many times is the row criterion more important than the column criterion for the evaluation of alternatives?" The comparison of criteria and sub-criteria were based on the scale in the Appendix. Pair-wise comparison for level 2 main criteria and level 3 sub-criteria are shown in the Tables 3 .

Four alternative $\mathrm{CNC}$ machines were evaluated on level 3 sub-criteria. In evaluating on economic criteria, the managers provided their judgment based on the already evaluated economic indicators. The judgment on the four $\mathrm{CNC}$ machines on level 3 sub-criteria was mainly dependent on the capabilities and attributes of the machines and hence participation of technically competent person (manufacturing

Table 3 - Pair-wise Comparison of Criteria

\begin{tabular}{lccc}
\hline $\begin{array}{l}\text { Main } \\
\text { criteria }\end{array}$ & $\begin{array}{c}\text { Economic } \\
\text { indicators }\end{array}$ & $\begin{array}{c}\text { Strategic } \\
\text { benefits }\end{array}$ & Risk \\
\hline $\begin{array}{l}\text { Economic } \\
\text { indicators }\end{array}$ & 1 & $1 / 2$ & 2 \\
$\begin{array}{l}\text { Strategic } \\
\text { benefits }\end{array}$ & 2 & 1 & 4 \\
$\begin{array}{l}\text { Risk } \\
\text { Inconsistency ratio }=0.00\end{array}$ & $1 / 2$ \\
\hline
\end{tabular}

\begin{tabular}{lcccc}
\hline $\begin{array}{l}\text { Sub criteria } \\
\text { of economic } \\
\text { indicators }\end{array}$ & PBP & ROI & IRR & NPV \\
\hline PBP & 1 & 3 & 2 & $1 / 3$ \\
ROI & $1 / 3$ & 1 & 1 & $1 / 5$ \\
IRR & $1 / 2$ & 1 & 1 & $1 / 5$ \\
NPV & 3 & 5 & 5 & 1 \\
& Inconsistency $=0.01$ & & \\
\hline
\end{tabular}

\begin{tabular}{|c|c|c|c|}
\hline $\begin{array}{l}\text { Sub } \\
\text { criteria of } \\
\text { strategic } \\
\text { benefits }\end{array}$ & TEC & BUS & $\mathrm{COM}$ \\
\hline TEC & 1 & $1 / 4$ & $1 / 3$ \\
\hline BUS & 4 & 1 & 1 \\
\hline $\mathrm{COM}$ & 3 & $1 / 2$ & 1 \\
\hline \multicolumn{4}{|c|}{ Inconsistency ratio $=0.01$} \\
\hline $\begin{array}{l}\text { Sub } \\
\text { criteria of } \\
\text { risk }\end{array}$ & FIR & ORR & TER \\
\hline FIR & 1 & 3 & 2 \\
\hline ORR & $1 / 3$ & 1 & 1 \\
\hline TER & $1 / 2$ & 1 & 1 \\
\hline \multicolumn{4}{|c|}{ Inconsistency ratio $=0.02$} \\
\hline
\end{tabular}


engineer) in the evaluation team was very important. Pair-wise comparison of alternatives for financial risk is shown in Table 4. Similar to the judgments in Table 4, pair-wise comparison of alternative CNC machines were obtained for each sub-criterion in level 3.

Table 4: Pair-wise Comparison of Alternative Technologies under Financial Risk

\begin{tabular}{ccccc}
\hline & CNC1 & CNC2 & CNC3 & CNC4 \\
\hline CNC1 & 1 & 2 & 3 & 4 \\
CNC2 & $1 / 2$ & 1 & 2 & 3 \\
CNC3 & $1 / 3$ & $1 / 2$ & 1 & 2 \\
CNC4 & $1 / 4$ & $1 / 3$ & $1 / 2$ & 1 \\
& Inconsistency ratio $=0.01$ & \\
\hline
\end{tabular}

In providing pair-wise comparison for both criteria and alternatives, there is a possibility for inconsistency in judgments. This study used Expert Choice software for calculation. The software indicates the inconsistency ratio of the judgments. If inconsistency ratio is more than 0.1 , the judgment should be reconsidered.

\subsection{Rating of alternative machines}

Using the Expert choice software, pair-wise comparisons were converted to the individual weights of criteria and alternative $\mathrm{CNC}$ machines. Resulting overall weights for $\mathrm{CNC}$ machines determined the ranking. Table 5 shows the overview of criterion and alternative weights.

Table 5 - Overview of Criterion and Alternative Weights

\begin{tabular}{lccccc}
\hline & & CNC & CNC & CNC & CNC \\
& & 1 & 2 & 3 & 4 \\
\hline $\begin{array}{l}\text { Economic } \\
\text { indicators }\end{array}$ & 0.286 & & & & \\
PBP & 0.230 & 0.477 & 0.288 & 0.154 & 0.081 \\
ROI & 0.098 & 0.121 & 0.158 & 0.376 & 0.346 \\
IRR & 0.107 & 0.095 & 0.160 & 0.277 & 0.467 \\
NPV & 0.565 & 0.088 & 0.157 & 0.272 & 0.483 \\
Strategic & 0.571 & & & & \\
benefits & & & & & \\
TEC & 0.126 & 0.167 & 0.167 & 0.333 & 0.333 \\
BUS & 0.458 & 0.095 & 0.160 & 0.277 & 0.467 \\
COM & 0.416 & 0.078 & 0.125 & 0.306 & 0.492 \\
Risk & 0.143 & & & & \\
FIR & 0.550 & 0.467 & 0.277 & 0.160 & 0.095 \\
ORR & 0.210 & 0.375 & 0.375 & 0.125 & 0.125 \\
TER & 0.240 & 0.121 & 0.158 & 0.346 & 0.376 \\
Overall & & 0.161 & 0.177 & 0.272 & 0.389 \\
rating & & & & & \\
Ranking & & 4 & 3 & 2 & 1 \\
\hline
\end{tabular}

Results shows that $\mathrm{CNC} 4$ (i.e. 5 -axis machine with rotary table and spindle) is the most attractive machine according to the preference given by the management. However, it can be seen that this alternative is not attractive in terms of payback period and certain risk factors. $\mathrm{CNC} 4$ shows a clear dominance in IRR, NPV and strategic benefits. The management is more favourable towards the strategic benefits and hence $\mathrm{CNC} 4$ has been prioritized as the best alternative. But this cannot be directly decided without proper evaluation process due to the complexity of the problem.

\section{Conclusions}

The analytical hierarchy process (AHP) provided a credible method to evaluate quantitative and qualitative aspects of a major investment decision. The use of the AHP enabled the management of the case company to systematically structure their decision making problem and to simultaneously evaluate all investment alternatives through a set of relevant criteria. A number of relevant points associated with the case study are summarized below:

- The feasibility of the AHP as a decision making tool for the justification of complex investment alternatives in AMT was successfully demonstrated.

- Different categories of criteria were considered in the decision making process.

- Inputs of managers from different background were considered in decision making. Therefore implementation of AMT will be more successful due to the support of different parties.

- The systematic approach of the AHP assisted managers to better understand the processes they used in reaching investment decisions.

- The decision support software, Expert Choice, facilitated the AHP application. Both AHP and Expert Choice appear to be flexible enough to support AMT justification in a wide variety of manufacturing environments. 
In spite of many advantages, use of AHP is additional effort due to certain reasons. Pairwise comparison needs longer time duration compared to assigning the direct weights on the criteria. Careful attention is required to avoid the inconsistency in the judgment. Capability of Expert Choice software for calculating the inconsistency ratio is much useful to avoid the inconsistencies of the judgment in the early stages.

Even though the results show the ranking based on the judgments given by the management, robustness of the results can be further analyzed using sensitivity analysis which is facilitated by Expert choice software.

\section{References}

1. Stainer, A., Ghobadian, A., Liu, J. \& Stainer, L., "Strategic investment appraisal for advanced manufacturing technology", International Journal of Materials and Product Technology, Vol. 11, No. 1-2, pp. 76-88, 1996.

2. Small, M.H., 'Planning, justifying and installing advanced manufacturing technology: a managerial framework', Journal of Manufacturing Technology Management, Vol. 18, No. 5, pp. 513-537, 2007.

3. Baldwin, J. and Lin, Z., "Impediments to advanced manufacturing technology adoption for Canadian manufacturers", Research Policy, Vol. 31, No. 8, pp. 1-18, 2002.

4. Boer, H., Hill, M. and Krabbendam, K., "FMS implementation management: promise and performance", International Journal of Operations Production Management, Vol. 10, No. 1, pp. 5-20, 1990.

5. Beatty, C.,"Implementing advanced manufacturing technology", Business Quarterly, Vol. 55, No. 2, pp. 46-50, 1990.

6. Small, M.H. and Chen, I.J., "Investment justification of advanced manufacturing technology: an empirical analysis", Journal of Engineering \& Technology Management, Vol. 12, pp. $27-55,1995$.
7. Lefley, F., Wharton, F., Hajek, L., Hynek, J. and Janecek, V., "Manufacturing investments in the Czech Republic: an international comparison", International Journal of Production Economics, Vol. 88, pp. 1-14, 2004.

8. Teng,K.L.L.andSeetharaman,A.,"Theselection and management of cost justification techniques among advanced manufacturing technology companies in Malaysia", International Journal of Management, Vol. 21, No. 1, pp. 45-50, 2004.

9. Chan, F.T.S., Chan, M.H., Lau, H. and Ip, R.W.L., "Investment appraisal techniques for advanced manufacturing technology (AMT): a literature review" Integrated Manufacturing Systems, Vol. 12, No.1, pp.35-47, 2001.

10. Sarkis, J., "Evaluating flexible manufacturing systems alternative using data envelopment analysis", The Engineering Economist, Vol. 43, No.1, pp. 25-47, 1997.

11. Merdith, J.R. and Hill, M.M., "Justifying new manufacturing systems: a managerial approach", Sloan Management Review, Vol. 28, No. 4, pp. 49-61, 1987.

12. Canada, J.R., "Evaluation of computerintegrated manufacturing systems", Proceedings, Annual International Industrial Engineering Conference, Los Angeles, CA, pp. 162-173, 1985.

13. O'Brien, C. and Smith, S.J.E., "Design of the decision process for strategic investment in advanced manufacturing systems", International Journal of Production Economics, Vol 30-31, pp. 309-322, 1993.

14. Suresh, N. and Meredith, J., "Justifying multimachine systems: an integrated strategic approach", Journal of Manufacturing Systems, Vol. 4, No. 2, pp. 117-134, 1985.

15. Zhao, H. and Co, H.C., "Adoption and implementation of advanced manufacturing technology in Singapore", International Journal of Production Economics, Vol. 48, pp. 7-19, 1997.

16. Fotsch, R., "Machine tool justification policies: Their effect on productivity and profitability", International Journal of Production Research, Vol. 20, pp. 169-195, 1984. 
17. Rosenthal, S., "A survey of factory automation in the US", Operations Management Review, Winter, pp. 41-8, 1984.

18. Primrose, P.L., Investment in Manufacturing Technology, Chapman and Hall, London, 1991.

19. Kakati, M. and Dhar, U.R., "Investment justification in flexible manufacturing systems", Engineering Costs and Production Economics, Vol. 21 No. 3, pp. 203 - 209, 1991.

20. Kaplan, R.S., "Yesterday's accounting undermines production", Harvard Business Review, Vol. 62 No. 4, pp. 95-101, 1984.

21. Slagmulder, R. and Bruggeman, W., "Investment justification of flexible manufacturing technologies: Inferences from field research", International Journal of Operations \& Production Management, Vol. 12, pp. 168-186, 1992.

22. Baldwin, C.Y., "How capital budgeting deters innovation and what to do about it", Research Technology Management, November/ December, pp. 39-45, 1991.

23. Krinsky, I. and Miltenburg, J., "Alternate method for the justification of advanced manufacturing technologies", International Journal of Production Research, Vol. 29 No. 5, pp. 997-1015, 1991.

24. Meredith, J.R. and Suresh, N., "Justification techniques for advanced manufacturing technologies", International Journal of Production Research, Vol. 24 No. 5, pp. 1043$58,1986$.

25. Ordoobadi, S.M. and Mulvaney, N.J., Development of a justification tool for advanced manufacturing technologies: system-wide benefits value analysis, Journal of Engineering and Technology Management, Vol. 18, pp. 157-184, 2001.

26. Sullivan, W.G., "Models IE's can use to include strategic, non-monetary factors in automation decisions", Industrial Engineering, Vol. 18, No. 3, 42-50, 1986.
27. Meredith, J.R. and Mantel, S.J., Project Management: A Managerial Approach, John Wiley \& Sons, New York, NY, 1985.

28. Sitkin, S.B. and Pablo, A.L., "Reconceptualising the determinants of risk behavior", Academy of Management Review, Vol. 17 No. 1, January, pp. 9-38, 1992.

29. Roger, N., "Justification of FMS with the Analytical Hierarchy Process", Journal of Manufacturing, 7 (3), pp. 175-182, 1987.

30. Saaty, T.L., Analytic Hierarchy Process, McGrawHill, New York, NY, 1980.

31. Duimering, R., Safeyeni, F. and Purdy, L., "Integrated manufacturing: redesign the organization before implementing flexible technology", Sloan Management Review, Vol. 34, pp. 47-55, 1993.

32. Zammuto, R. F. and O'Connor, E. J., "Gaining advanced manufacturing technologies' benefits: the role of organizational design and culture", Academy of Management Review, Vol. 17, 701-728, 1992. 
Appendix: Scale of Relative Importance

\begin{tabular}{cll}
\hline Intensity & Definition & Explanation \\
\hline 1 & $\begin{array}{l}\text { Equal Importance } \\
\text { Weak importance of } \\
\text { one over the other } \\
\text { Essential or strong } \\
\text { Very strong }\end{array}$ & $\begin{array}{l}\text { Two activities contribute equally to the objective } \\
\text { Experience and judgment slightly favour one } \\
\text { another }\end{array}$ \\
$\begin{array}{l}\text { Experience and judgment strongly favour one another } \\
\text { An activity is strongly importance favoured and } \\
\text { its dominance is demonstrated in practice } \\
\text { The evidence favouring one activity over another } \\
\text { is of the highest degree } \\
\text { When compromise is needed }\end{array}$ \\
\hline
\end{tabular}

